\title{
JUSTICIA RESTAURATIVA: LA DESATINADA PROHIBICIÓN DE LA MEDIACIÓN PENAL EN LOS ASUNTOS DE VIOLENCIA DE GÉNERO
}

\author{
CARLOS PATRICIO SERRANO LUCERO ${ }^{1}$
}

\section{RESUMEN}

La violencia de género es un fenómeno que ha pasado de ser ignorado por la norma penal a tener una excesiva carga punitiva en la actualidad. Esto ha llevado, entre otras cosas, a la prohibición de la mediación penal en asuntos de violencia de género. La política criminal actual no ha dado resultado pues los índices de violencia de género no han disminuido. En el presente aporte se argumentará a favor de la implementación de la mediación penal en determinados asuntos de violencia de género, explicando, para ello, las infundadas causas de su prohibición y abogando por los beneficios que ofrece este sistema de justicia restaurativa.

\section{PALABRAS CLAVE:}

Violencia de género; justicia restaurativa; mediación penal.

1 Estudiante del Master Oficial en Justicia Criminal por la Universidad Carlos III de Madrid 


\begin{abstract}
Gender-based violence is a phenomenon that has gone from being ignored by the criminal law to becoming an excessive punitive burden today. This has led to, among other things, the prohibition of criminal mediation in matters of gender violence. The current criminal policy has not been as rates resulting gender violence have not decreased. In this contribution we will argue in favor of the implementation of criminal mediation in certain cases of gender violence, explaining the unfounded reasons for it being banned and advocating the benefits offered by this system of restorative justice.
\end{abstract}

KEY WORDS: Gender violence; restorative justice; criminal mediation. 


\section{ESTADO DE LA CUESTIÓN. CRÍTICAS AL SISTEMA DE JUSTICIA CONTENCIOSO TRADICIONAL}

En este epígrafe no me referiré a la justicia restaurativa, pues en su lugar, es necesario en primer plano, conocer ciertas características del sistema de justicia contencioso tradicional con el fin de evidenciar algunas de sus falencias y así dar sentido a la intervención de la justicia restaurativa en los diferentes procesos judiciales.

Para abordar el presente análisis es necesario admitir que el conflicto es parte de la condición humana. El hecho de que los seres humanos vivamos en sociedad predispone el conflicto, por ello la sociedad ha constatado la necesidad de implantar un sistema que ayude a la solución de controversias entre individuos. En este marco, en las últimas décadas los sistemas judiciales contenciosos han sido los protagonistas. Dicho sistema ha sido implantando por el Estado de derecho y tradicionalmente cuenta con dos únicas respuestas para sus usuarios: ganar o perder. Así, una tercera persona ajena al conflicto será quien tenga el poder de decidir quién ha ganado y quién ha perdido la disputa, olvidándose, en la mayoría de ocasiones, de cumplir las expectativas de los requirentes de justicia ${ }^{2}$.

El sistema de justica tradicional desde su invención ha intentado mantenerse en pie y solventar todas las causas que han ingresado en este, no obstante, al parecer no responde a las exigencias esperadas. Así por ejemplo, dentro de la justicia penal no se han

2 Vid. Díaz Madrigal, I.N.: La mediación en el sistema de justicia penal: justicia restaurativa en México y España, Universidad Nacional Autónoma de México, México DF, 2013, pp. 1-2 
cumplido concepciones teóricas que sin duda ponen en peligro la eficacia del sistema actual, entre ellos, el fin de la pena: la prevención ${ }^{3}$. En efecto, el mismo aislamiento de los delincuentes, a mi criterio, es totalmente contrario a la resocialización y ello se verifica en la práctica.

Además de la brecha entre lo teórico y práctico, dentro del sistema judicial actual es también importante resaltar la rigidez del mismo, pues, en cuanto a normas procesales respecta, el sistema judicial penal tradicional supone una única vía con características invariables, lo cual en consecuencia, minimiza toda posibilidad de modificación del proceso en beneficio común de las partes.

A pesar de lo antes señalado, es evidente la evolución del derecho respeto al pasado, en tal sentido hemos de aceptar que el derecho penal contemporáneo ha tendido a la humanización. Para justificar tal afirmación es necesario recordar, entre otros, a BECCARIA ${ }^{4}$ quien denunció las penas inhumanas y el ejercicio

3 Los actuales sistemas de justicia penal se centran en la prevención (al menos teóricamente), entendida esta prevención como la resocialización del delincuente, de ahí que la Constitución española contempla en su artículo 25.2 "Las penas privativas de libertad y las medidas de seguridad estarán orientadas hacia la reeducación y reinserción social y no podrán consistir en trabajos forzados...". En el mismo sentido la constitución Ecuatoriana en su artículo Art. 201 dice "El sistema de rehabilitación social tendrá como finalidad la rehabilitación integral de las personas sentenciadas penalmente para reinsertarlas en la sociedad, así como la protección de las personas privadas de libertad y la garantía de sus derechos. El sistema tendrá como prioridad el desarrollo de las capacidades de las personas sentenciadas penalmente para ejercer sus derechos y cumplir sus responsabilidades al recuperar la libertad".

4 Sobre este tema, véase, en general: BECCARIA, C.: Tratado de los delitos y las penas, Universidad Carlos III de Madrid, Madrid, 2015. 
abusivo del poder estatal en su época. Actualmente, a pesar de haber conseguido cierta evolución en la humanización de las penas, la relativa -y a mi criterio simbólica- inclusión de las víctimas en los sistemas penales, el aumento de garantías de los procesados, y en general el mejoramiento de la administración de justicia penal respecto a tiempos pasados; es necesario aceptar también, que hasta el momento no se ha conseguido que el sistema judicial responda de forma más humana al requerimiento de sus usuarios, pues lo que se observa actualmente, es una justicia fría y mecánica con reglas tasadas que en ocasiones olvida que el ser humano y su dignidad es el fin último de la justicia.

Si centramos nuestra atención en las encuestas a nivel iberoamericano, se podrá verificar que la eficacia del sistema judicial penal no cumple las expectativas esperadas ${ }^{5}$. Las personas tienden a desconfiar de la justicia a tal punto que algunos autores

Disponible en formato digital en: http:/ / goo.gl/2TNZaK

5 Así, para conocer las cifras de los distintos países de América Latina se podrá revisar el "Proyecto de Opinión Pública de América Latina" (Vanderbilt University) en http://goo.gl/DPYEZj. Vale mencionar que en este estudio Ecuador figura dentro de los siete países más destacados, no obstante, a pesar de ello, tanto Ecuador como Latinoamérica en general continúan aún rezagados, pues constituye sin duda, un signo de mediocridad aceptar la realidad o enorgullecerse de ella a sabiendas de que el sistemas judicial actual en Ecuador vive una gran crisis, incluso, evidenciándose diferentes protestas de distintos colectivos, entre ellos el gremio de abogados que constantemente pide independencia del poder judicial respecto al resto de poderes del Estado. Por otro lado España aunque lleva cierta ventaja respecto a los países latinoamericanos no ha logrado cumplir expectativas esperadas, en tal sentido puede revisarse el informe emitido por el Consejo General del Poder Judicial en http://goo.gl/uIFEc3 o en su defecto, los informes y barómetros sobre la Actividad de la Justicia en Fundación Wolster Kluwer: http://goo.gl/ZNX2i6. 
han afirmado que el derecho penal se encuentra en crisis. Sumado a lo anterior, no se puede dejar de hablar de la globalización, la aparición de las nuevas tecnologías y la creación de lo que se denomina "la sociedad de riesgo" donde los ordenamientos jurídico penales han aumentado y se han incluido tipos penales de riesgo, convirtiéndose la vía penal, en la favorita al momento de legislar, transformando, la mínima intervención penal en una máxima intervención del ius puniendi ${ }^{7}$.

La expansión del derecho penal ha conllevado, en parte, a la judicialización de conductas que pueden ser solventadas por otras vías diferentes a las penales. Sumado a ello, hay que considerar que la sociedad cada vez más tiende a la judicialización de sus pleitos, creando una cultura de litigio $^{8}$. Dicho fenómeno se traduce en la "necesidad imperante" y a la vez innecesaria de una respuesta judicial frente a todos los conflictos, incluso, por más insignificantes que estos constituyan ${ }^{9}$.

6 Término acuñado por el filósofo alemán Urlich BECK, quien se refirió así por primera vez a la evolución postmoderna de la sociedad. Sobre el tema véase, en general: BECK, U.: La sociedad de riesgo. Hacia una nueva modernidad, Paidós, Barcelona, 1998.

7 Vid. SILVA SÁNCHEZ, J.M.: La expansión del derecho penal aspectos de la politica criminal en las sociedades postindustriales, Civitas, Madrid, 2001, pp. 20 y ss.

8 Vid. Perulero García, D.: "Hacia un modelo dejusticia restaurativa: la mediación penal.", Sobre la Mediación Penal (posibilidades y limites en un entorno de reforma del Proceso Penal Español) (dir. P.M. Garciandía González y h. Soleto), Aranzadi, Pamplona, 2012, p. 71.

9 Así, Diana Perulero acertadamente dice: “Quizá subsista la desafortunada percepción de que el Derecho es el medio adecuado para la solución de muchos más problemas, también personales, de los que realmente puede solventar, ya que no es más que un instrumento necesario para la solución de litigios estrictamente jurídicos, por lo que el conflicto real que subyace no sólo no se 
Finalmente, es acertado señalar que el sistema penal tradicional cuenta con varias falencias en cuanto a atención a la parte humana corresponde. En tal sentido, la víctima no se siente escuchada además de desatendida toda vez que el Estado en muchas ocasiones aprovecha de ella simplemente como una prueba más para la comprobación del delito. En esta línea, no me puedo resistir a transcribir la acertada explicación del maestro ZAFFARONI:

Lo comprobamos en cualquier caso: si una persona agrede a otra y le quiebra un hueso, el estado se lleva al agresor, lo pena alegando que lo hace para disuadir a otros de romper huesos o para enseñarle a no hacerlo o para lo que sea, el que sufre el hueso roto debe acudir a la justicia civil, en la que no puede obtener nada si el agresor no tiene bienes. El poder punitivo redujo a la persona con el hueso roto a un mero dato, porque no toma parte en la decisión punitiva del conflicto. Más aún: debe mostrar su hueso roto y si no lo hace el poder punitivo la amenaza como testigo remiso y puede llevarla por la fuerza a mostrar lo que el agresor le hizo. La característica del poder punitivo es, pues, la confiscación de la víctima, o sea, que es un modelo que no resuelve el conflicto porque una de las partes (el lesionado) está por definición excluida de la decisión. Lo punitivo no resuelve el conflicto sino que lo cuelga, como una prenda que se seca en el lavarropas y se tiende en la soga hasta que se seque. Encerramos al agresor un tiempo y lo soltamos cuando el conflicto se secó. Es cierto que podemos matarlo, pero en ese caso no haríamos otra cosa que dejar el conflicto

resuelve, sino que frecuentemente se agudiza en un proceso judicial." En ibídem. 
colgado para siempre. A la víctima no le reponemos nada, no le pagamos el tratamiento, el tiempo laboral perdido, nada. Ni siquiera le damos un diploma de víctima para que lo cuelgue en un rincón de la casa. ${ }^{10}$

Por lo explicado se concluye que el sistema de justicia penal tradicional presenta varias inconsistencias en tanto no cumple con preceptos teóricos que en la práctica han sido inalcanzables debido a su rigidez y autoalimentación lo cual bloquea, en principio, otras vías alternativas diferentes a las oficiales. En contraposición a esta postura y como herramienta alternativa o complementaria al sistema de justicia tradicional, ha tomado fuerza la justicia restaurativa, constituyéndose esta, en una vía eficaz a la solución de conflictos.

Con lo antes dicho no se afirma el fracaso total del sistema judicial contencioso, pues apuntar a ello sería poco más que irracional toda vez que son innegables los avances que hemos tenido en la justicia durante las últimas décadas. Lo que se pretende es evidenciar ciertos desatinos que podrían ser solventados por vías diferentes a las tradicionales concediéndole un espacio merecido a la justicia restaurativa.

\section{UN BREVE RECORRIDO EN LA HISTORIA: EL ORIGEN DE LA JUSTICIA RESTAURATIVA Y SUS DIFICULTADES.}

En torno al nacimiento de la justicia restaurativa han surgido varias dudas que hasta la actualidad se mantienen. Por una parte están presentes quienes aseguran que la justicia restaurativa tiene sus orígenes en la justicia indígena pues, a su criterio, las 
características de la justicia indígena son parecidas a las aplicables en la justicia restaurativa, lo cual tiene lógica y es acertado ${ }^{11}$, sin embargo, afirmar que la justicia restaurativa es similar a la justicia indígena, a mi juicio, no justifica su origen.

En contraposición al pensamiento anterior, y con tendencia mayoritaria encontramos la idea que relaciona el inicio de la justicia restaurativa con varios factores que se han desarrollado en el tiempo. En tal sentido, es errado afirmar que la justicia restaurativa y sus singulares características han devenido de una exclusiva consecuencia, por el contrario, lo que ha dado vida a esta actual tendencia es la lucha constantes de distintos colectivos, que hasta la actualidad, apuntan en pro de una justicia diferente a la contenciosa.

Entre los antecedentes que aportaron a la evolución de la justicia restaurativa es preciso señalar: El movimiento crítico de las instituciones represivas: en el año 1950 en los Estados Unidos de Norteamérica comenzó la ola de protestas en contra de la violencia racial y de género. Los movimientos victimarios: buscaron y

11 Así, en la justicia indígena ecuatoriana se pueden verificar varias características que empatan con las propuestas por la justicia restaurativa, entre estas la tendencia a buscar una reconstrucción de la comunidad, el arrepentimiento del delincuente y sobre todo la reparación a la víctima, en tal sentido, Gerardo NiEves LojA dice: "En la justicia indígena ningún acto (delito) que altera la armonía comunitaria, queda en la impunidad. Se trata de "salvar" la comunidad mediante la aplicación de la justicia indígena, cuyas resoluciones han sido verdaderas experiencias reconstructivas tanto individuales como colectivas. Aquí, "la reflexión y el entendimiento de las partes" son instancias que conducen al perdón, a la reconciliación y a la reconstrucción." En NIEVES LOJA, G.: "El carácter reconstructivo de la justicia indígena, Chimborazo, Ecuador: perspectiva ética." , Aufklärung: revista de filosofía, V2.N2, 2015, p. 86. 
lograron el mayor posicionamiento de la víctima en el proceso, se centraron en la reparación y la visualización de la violencia de género que en aquel entonces carecía de protagonismo. Movimientos que buscaron la valorización de la comunidad: en los años sesenta del siglo pasado, se apuesta por el retorno al modo de vida comunitario donde los problemas eran solventados de mejor manera. Movimiento de descolonización: entre 1960 y 1970 se vuelve la mirada a la forma de solución de conflicto de pueblos ancestrales y se intenta recuperar dichos valores ahí aplicados. Trasformaciones estructurales: entre 1973 y 1979 se verifica la descentralización de poderes donde la intervención estatal queda en segundo plano ${ }^{12}$.

Ahora bien, luego de anunciar brevemente los antecedentes que llevaron al génesis de lo que ahora se conoce como justicia restaurativa, es menester citar lo que el pensamiento mayoritario identifica como el primer proceso restaurativo, así, dicho acontecimiento fue llevado a cabo en el año de 1974 en la provincia de Ontario en Canadá, donde surgieron varios procesos de mediación penal dirigidos por la iglesia Menonita "Mennonite Central Committee" y autorizados por diversos tribunales de justicia donde se obtuvieron resultados magníficos, tomando dicha experiencia como ejemplo para aplicarla en el resto del país ${ }^{13}$. Por los resultados alentadores arrojados por la experiencia canadiense, los Estados Unidos de Norteamérica implementaron el Victim/ Offender Reconciliation Program (VORP) o Victim Offender Mediation (VOM). Programas en los cuales las víctimas y agresores

12 DíAz MAdrigal, I.N.: La medi..., op., cit., pp. 27-32.

13 Vid. Mera González-Ballesteros, A.: “Justicia restaurativa y proceso penal garantías procesales: límites y posibilidades", Revista Ius et Praxis, No 2, 2015, p. 169. 
con la ayuda de mediadores, mantenían sesiones de mediación penal, extendiéndose esta tendencia a países con sistemas de justicia anglosajón como Nueva Zelanda y Australia ${ }^{14}$.

Ulteriormente, la justicia restaurativa mediante la mediación penal ha logrado un gran impulso trasladándose no solamente de país a país, sino también, de continente a continente, migrando del common law al civil law, cuestión que no fue nada fácil, toda vez que los autores clásicos de derecho penal continental avistaban incrédulos los conceptos de este reciente y novedoso sistema, que a su criterio, vulneraba la institucionalización y reglas del derecho que ellos habían robustecido por años.

No se puede negar lo complejo y lento que ha sido introducir las ideas de la justicia restaurativa en el sistema tradicional, y de ello pueden dar fe quienes ya se vienen dedicando muchos años a intentar introducir conceptos restaurativos, y mediación en la administración de justicia. Aquellos pioneros en la promoción de la justicia restaurativa fueron, sin duda, quienes constataron la incredulidad de los clásicos creyentes de la justicia contenciosa frente a este nuevo sistema.

Recuerdo cuando Helena SolEto hablaba sobre el inicio de la justicia restaurativa en España y explicaba que fueron muy pocos los que creían en este sistema y que incluso, cuando ella y sus colegas sustentaban pensamientos de carácter restaurativo y medicación penal a quienes habían vivido siempre creyendo en un sistema tradicional, los receptores pensaban que se hablaba de

14 TAMARIT Sumalla, J.: “La justicia restaurativa: concepto, principios, investigación y marco teórico", La justicia restaurativa: desarrollo y aplicaciones, Comares, Granada, 2012, pp. 3-4. 
fantasías, suponiendo ex ante, que el delincuente nunca podría aceptar su error y mucho menos reparar el daño ocasionado a la víctima $^{15}$. En el mismo sentido, la ex magistrada Ana Carrascosa, en su intervención había hecho hincapié sobre la falta de recursos designados por el Estado para la implementación de la mediación en materia penal, donde faltaba personal e infraestructura que ahora, poco a poco, ha ido incrementando ${ }^{16}$.

La situación en Ecuador no ha sido diferente. Recordemos que la mediación en materia no penal ya ha sido promovida por legislaciones anteriores, sin embargo, respecto a la medicación penal la normativa que viene a tratar el tema como tal, es sin duda, el Código Orgánico Integral Penal que entró en vigencia el mes agosto del año 2014. Este cuerpo normativo contiene en su título $\mathrm{X}$ lo que el legislador ha denominado textualmente como "Mecanismo Alternativos de Solución de Conflictos".

Incluir mecanismos alternativos de solución de conflictos en materia penal en el Ecuador obedece al cambio de paradigma mundial que ha puesto en duda a la efectividad del derecho penal retribucionista. Las dificultades que ha tenido España frente a la implementación de infraestructura para el ejercicio de la medición penal también lo ha sufrido Ecuador, en ese contexto el Estado ecuatoriano ha tenido que invertir tanto en personal como

15 Ponencia sobre Justicia Restaurativa, Dra. Helena SOLETO, profesora titular de Derecho Procesal de la Universidad Carlos III de Madrid, ponencia impartida el día 11 de enero de 2016 en la Universidad Carlos III de Madrid campus Puerta Toledo, Madrid.

16 Ponencia sobre Justicia Restaurativa, Da. Ana CARRAscosA, Ex Magistrada, Jefe de sección de Estudios e Informes del Consejo General de Poder Judicial, impartida el día 11 de enero de 2016 en la Universidad Carlos III de Madrid campus Puerta Toledo, Madrid. 
en bienes materiales para intentar introducir en el sistema judicial penal la mediación, sin llegar, hasta el momento, a cumplir las expectativas esperadas.

La lucha constante de quienes creen en la justicia restaurativa y sus resultados favorables, sin duda ha logrado que se apueste por esta vía. En la actualidad, la introducción de la medición penal en los procesos tradicionales se ha logrado gracias a las transformaciones sociales que se han dado en las últimas décadas, el apoyo de los órganos supranacionales ${ }^{17}$ y la aprobación legislativa de normas que permiten procesos de mediación penal centrados en la reparación.

A pesar de los grandes problemas que ha sufrido la mediación penal al abrirse camino en el sistema tradicional, al parecer esta rama del derecho cada vez va conquistando más adeptos que apuntan por ella.

\section{LA EXCESIVA RESPUESTA PUNITIVA COMO "ÚNICA" VÍA DE SOLUCIÓN A LA VIOLENCIA DE GÉNERO.}

Previo a entrar al análisis de la justicia restaurativa con relación a la violencia de género, es ineludible recordar la evolución de la

17 A modo de ejemplo, se podrá revisar la Resolución 1999/26, del 28 de julio de 1999 y la Resolución 2000/14, del 7 de julio de 2000 del Consejo Económico y Social sobre la mediación penal y justicia reparadora respectivamente, dentro del ámbito de las Naciones Unidas. Sin embargo, existen, además de lo citado, un sin número de pronunciamientos a favor de la Justicia Restaurativa por parte de organismos internacionales, lo cual evidencia la voluntad para con este sistema. Para mayor profundidad sobre normas internacionales y europeas con relación al tema véase TAMARIT SUMALLA, J.: "La just..., op., cit., p. 24-30. 
respuesta punitiva frente a este fenómeno. Si damos una mirada retrospectiva, podremos constatar la falta de respuesta punitiva a las conductas de violencia de género. Así pues, no es extraño que hace unas décadas el pensamiento mayoritario de la sociedad considere que los "problemas de casa se los arreglen en casa" y en ese tenor, el poder punitivo y la intervención penal con relación a los supuesto de violencia de género, se mantenían al margen.

Lo anterior ha cambiado y en efecto ha evolucionado con distintas corrientes, entre las cuales ha predominado la feminista.

La tendencia actual frente a la violencia de género consiste -contrariamente al pensamiento pasado-en la protección de la mujer y la reivindicación de sus derechos. Actualmente la sociedad y los medios de comunicación están alerta sobre las conductas machistas toda vez que aquello se repudia y causa vergüenza, desatándose así, una creciente alarma social, que ha devenido, "como no podía ser de otra manera"18, en la implementación de normas penales que sancionen tal conducta. Para intentar mitigar la violencia de género, los Estados, mediante sus órganos legislativos han

18 A mi criterio, la implementación de normas penales per se no soluciona ningún problema social, sin embargo, el legislador al parecer cree que la implementación de una norma penal frente a un problema social es una consecuencia lógica, lo cual es desacertado. Dicho lo anterior no apunto a la despenalización de la violencia machista, toda vez que la sanción a este tipo de conductas es necesaria, no obstante, la respuesta punitiva a ciertas conductas tan complejas como la analizada deben ir acompañada además del derecho penal, de otras ciencias auxiliares y por qué no, de la justicia restaurativa. Sobre la necesidad y relación de otras ciencias en el derecho penal véase ZAFFARONI, E.: Estructura básica del derecho penal, Ediar, Buenos Aires, 2011, pp. 36-37. 
implementado un gran número de tipos penales ${ }^{19} \mathrm{y}$ procedimientos que evidentemente, tienden a un solo fin: el retribucionista ${ }^{20}$, que consiste, indiscutiblemente, en el inevitable castigo al agresor.

Siendo esto así, la pregunta es la siguiente: ¿la respuesta punitiva a este tipo de delitos ha tenido éxito en cuanto a prevención?

La implementación de normas penales para sancionar la violencia de género no ha ayudado a mitigar las agresiones, pues como era de esperar, al asumir un modelo retribucionista y centrado en el castigo, la comisión de este tipo de delitos no ha reducido. En España, el número de víctimas de violencia de género con orden de protección o medidas cautelares inscritas en el registro dentro del año 2015 han sido 27.624, mientras que en el 2014 fueron 27.087, cifra que se asimila a la obtenida en el año 2013 cuando se registraron 27.122 víctimas $^{21}$. Por lo aquí visto, se podrá evidenciar una constante que se mantiene en el número de víctimas en los

19 Tanto en Ecuador como en España se puede verificar en los últimos tiempos un aumento de normas penales en cuanto a violencia machista supone, así, Ecuador ha incluido incluso el tipo penal de femicidio, cuestión que en España todavía continúa en debate. Ello no quiere decir que nuestra legislación sea más avanzada que la española toda vez que se deberá legislar de acuerdo a las necesidades de cada sociedad. En todo caso, lo que se debe resaltar en ambas legislaciones es un aumento punitivo cualitativo y cuantitativo frente a la violencia de género.

20 El retribucionismo penal se basa en el castigo delincuente sin que se busque, en ningún caso, otro fin como la compensación o reparación a la víctima, la rehabilitación del delincuente y su posterior reinserción a la sociedad.

21 Cifras tomadas de la nota de prensa del Instituto Nacional de Estadística Español. Publicado el 7 de junio de 2016, recupero de: http://goo.gl/6HSK06 
tres últimos años, aumentado un $2.0 \%$ en el año 2015 con relación al $2014^{22}$.

En Ecuador ${ }^{23}$, la Fiscalía General del Estado ha registrado 2.150 denuncias de violencia intrafamiliar en el año 2012, mientras que en el año 2013 se han verificado 2.227, lo cual ha aumentado para el año 2014, encontrándose 1.350 denuncias desde el 1 de enero hasta el 10 de agosto (fecha en la cual entro en vigencia el Código Orgánico Integral Penal) y, en lo posterior, es decir del 10 de agosto al 31 de diciembre de 2014 constan 3.748 denuncias más, que en total suman 5.102 denuncias dentro del año $2014^{24}$. En el mismo sentido se han ingresado 25.335 causas sobre violencia de género en la Función Judicial a nivel nacional, esta cifra se ha contabilizado del periodo de agosto de 2014 a octubre de $2015^{25}$. De estas causas solamente han sido sentenciadas 950 hasta la fecha de corte del citado estudio que data de octubre de $2015^{26}$.

22

23

Ibídem

Con relación a las cifras de Ecuador se debe advertir que los datos que constan en el presente aporte han sido recopilados de portales electrónicos de noticias debido a la falta de estudios actualizados por parte del Estado toda vez que el censo oficial más reciente respecto a violencia de género publicado en el Instituto Nacional de Estadísticas y Censos data del año 2011 y analiza la violencia de género desde una perspectiva territorial interna y en una línea de tiempo, lo cual es indispensable para el presente estudio. Sin embargo, dicho estudio puede verificarse en: http://goo.gl/ofM335

Cifras tomadas del portal electrónico Focus Ecuador que a su vez cita a la Fiscalía General del estado. Publicado el 26 de mayo de 2015, recuperado de: http:/ /goo.gl/POenHD

Cifras tomadas del portal electrónico Expreso.ec que a su vez cita en un gráfico a la Función Judicial. Publicado en 22 de noviembre de 2015, recuperado de: http:/ /goo.gl/rsBdf7

Ibídem. 
Lo anterior demuestra, sin duda, la falta de eficacia del sistema en cuanto a prevención. Así, la justicia contenciosa enfrenta una vez más a los intervinientes del pleito creando más problemas de los que espera solucionar, pues, en efecto, tanto la víctima como el victimario están obligados a seguir el proceso que el sistema les ha impuesto y con ello la necesaria declaración de una pena, que en la mayoría de los casos, no satisface a la víctima.

Con todo lo dicho se llega a reafirmar la ineficacia del sistema contencioso y parte importante de dicho fracaso, corresponde, a mi criterio, a la prohibición de mediación penal en asuntos de violencia de género que será analizada en el siguiente epígrafe.

\section{LA MEDIACIÓN PENAL EN LOS SUPUESTOS DE VIOLENCIA DE GÉNERO}

Se podría creer que la Justicia Restaurativa es aplicable únicamente a delitos leves o en jurisdicción de menores, no obstante en contra de todo pronóstico, han tenido éxito un sin número de procesos restaurativos en delitos graves y además violentos como es el homicidio, el asesinato o incluso la violación ${ }^{27}$.

Entonces, si la justicia restaurativa ha sido aplicada incluso en casos tan graves como los anunciados ¿por qué no es posible aplicar procesos restaurativos en supuestos de violencia doméstica o de género? La respuesta es simple: el legislador lo ha prohibido.

27 Estos procesos han sido realizados en los Estados Unidos de Norteamérica, concretamente en Ohio y Texas. Vid. VillacAMPA EsTIARTE, C.: "La justicia restaurativa en los supuestos de violencia doméstica (y de género)", La justicia restaurativa: desarrollo y aplicaciones, Comares, Granada, 2012, p. 90. 
En efecto, España mediante la Ley Orgánica de Medidas de Protección Integral contra la Violencia de Género 1/2004, de 28 de diciembre ${ }^{28}$ prohíbe la medición penal imposibilitando a los Juzgados de Violencia sobre la Mujer la tramitación de este tipo de procedimientos.

Una segmento de la doctrina, por su parte ha puesto en relieve ciertas vías por las cuales, "al parecer", se podrían aplicar la mediación penal en supuestos de violencia de género ${ }^{29}$. Aquel pensamiento suponen que el legislador al prohibir estrictamente la mediación penal en los "Juzgados de Violencia sobre la Mujer" ha dejado abierta la posibilidad de mediar en los asuntos de violencia de género que son tramitados, por distintos motivos, en los Juzgados de Instrucción. Aquel argumento no corresponde ser profundizado para el presente estudio toda vez que lo que se busca constatar y resaltar es la inminente negativa del legislador para con la medicación penal en los supuestos de violencia de género.

Dentro de la misma línea, cierta parte de la doctrina española también ha puesto de manifiesto su malestar respecto a la prohibición de la mediación penal en asuntos de violencia de género debido a que aquella prohibición ha sido introducida en el año 2004, es decir, cuando ni siquiera existía una ley que regulará

28 En su art. 44 añade el art. 87 ter a la ley Orgánica del Poder Judicial constando en su numeral 5: " En todos estos casos está vedada la mediación."

29 Para profundizar sobre este tema Vid. OuBIÑA BARBOlla, S.: “La distancia que les separa, la distancia que nos separa: mediación en casos de violencia doméstica en España y en otros sistemas." Sobre la Mediación Penal (posibilidades y limites en un entorno de reforma del Proceso Penal Español) (Dir. Pedro M. Garciandía González y Helena Soleto), Aranzadi, Pamplona, 2012 pp. 188-189. 
la mediación en el ámbito criminal en general. Por lo dicho, no se cree correcto prohibir algo que aún ni siquiera había existido ${ }^{30}$. Esta prematura prohibición de la mediación penal en asuntos de violencia de género deja ver el carácter retribucionista que ha mantenido el legislador desde la introducción de la prohibición hasta la actualidad.

En todo caso, se reitera que a efectos del presente estudio lo que nos interesa es resaltar la negativa del legislador español frente a la implementación de procedimientos restaurativos en los supuestos de violencia de género, lo cual, como veremos, se verifica también en la legislación penal ecuatoriana.

En efecto, el legislador ecuatoriano en la reforma del año 2009 incluyó en el Código Penal del año 2000 la prohibición de acuerdos reparatorios en supuestos de violencia intrafamiliar. Así, el artículo 37 en su parte pertinente decía "No cabe conversión: (...) c) cuando se trate de delitos de violencia sexual, violencia intrafamiliar o delitos de odio" con esta prohibición a la conversión se negaba la posibilidad de realizar un acuerdo reparatorio debido a que en el artículo siguiente, esto es, el 37.1 decía "Excepto en los delitos en los que no cabe conversión según el artículo anterior, el procesado y el ofendido podrán convenir acuerdos de reparación..." En tal virtud, con los preceptos normativos antes citados quedó restringida toda posibilidad de mediación penal en un contexto restaurativo.

De igual manera, con la entrada en vigencia del Código Orgánico Integral Penal en agosto de 2014, en su título X, artículo 662 y

30 Vid. CANo SolER, M.A.: La mediación penal, Aranzadi, Pamplona, 2015, pp. 183-184. 
siguientes se ha regulado la forma y los supuestos en los cuales se permite la medicación penal. Así, dicho cuerpo normativo en su artículo 663 dice "La conciliación podrá presentarse hasta antes de la conclusión de la etapa de instrucción fiscal en los siguientes casos..." dando a conocer tres supuestos por los cuales se permite la conciliación, sin embargo, en la última parte el artículo concluye "se excluye de este procedimiento las infracciones (...) delitos contra la mujer o miembros del núcleo familiar" constatándose así la prohibición de mediación en asuntos de violencia de género por imperativo legal.

Por tanto, dentro de la legislación ecuatoriana como española se encuentra vedada la mediación penal en asuntos de violencia de género.

Luego de revisadas ambas legislaciones no se encuentra justificativo alguno sobre el cual descanse esta prohibición. Tampoco existe ningún pronunciamiento oficial del órgano legislativo competente al respecto.

Lo anterior, a mi criterio, nos lleva a pensar que la implementación de esta prohibición por parte del legislador obedece al cambio de paradigma social que ha tenido la violencia machista. En tal sentido, como en líneas anteriores se ha explicado, se entenderá que aquel fenómeno pasó de estar desapercibido a tener un exceso de persecución punitiva, lo cual sin duda derivó incluso en la prohibición de mediación con fines restaurativos.

Por otra parte, la doctrina, con un poco más de juicio ha desarrollado ciertos fundamentos que justifican la prohibición de la mediación en supuestos de violencia de género entre los cuales resalta, por ejemplo la falta de igualdad entre las partes. La 
mediación penal parte de la idea de igualdad, por ello es necesario que las partes estén en equivalencia. En esta línea, existe cierta corriente doctrinaria que sostiene que en asuntos de violencia de género la igualdad ha desaparecido, toda vez que el mismo hecho de la relación maltratadora, supone una superioridad del hombre sobre la mujer. Bajo la misma corriente, existen autores que sostienen que aplicar la mediación en asuntos de violencia de género, no solamente admite un perjuicio la víctima sino además, permite que se den nuevos maltratos considerando que, debido a la mediación, la víctima no ha podido salir del círculo maltratador y lograr su independencia. Finalmente hay quienes sostienen que someter a la víctima a un proceso de mediación supone un peligro para la seguridad de esta de tal modo que se puede lesionar su integridad tanto física como psíquica ${ }^{31}$.

De forma contraria al pensamiento antes expuesto ha ido tomando fuerza la corriente doctrinaria que critica la prohibición de la mediación en supuestos de violencia de género.

Para realizar un buen trabajo argumentativo a favor de la implementación de la medición penal en supuestos de violencia de género es necesario partir de pluralidad. Todos los casos de violencia de género nacen de conductas humanas en diferentes entornos, escenarios o circunstancias. Tal diversidad es impredecible debido a que en las diferentes relaciones personales podemos encontrar una infinidad de conductas que no pueden ser generalizadas. En tal sentido, no se podrá, obviamente, dar

31 Para mayor detalle sobre las corrientes doctrinarias a favor de la prohibición de la medicación en violencia de género véase CANO SOLER, M. A.: La medi..., op., cit., pp. 198-199. Así como también en Villacampa Estiarte, C.: “La justicia..., op., cit., pp. 99 y ss. 
el mismo tratamiento al maltratador enfermizo que terminó con la vida de su novia al finalizar la relación, que al joven de 18 años que insultó a su pareja ${ }^{32}$. Con esta ejemplificación no se pretende negar la gravedad que supone la violencia machista, pues por el contrario, lo que se busca con el proceso restaurativo es la eliminación de este fenómeno criminal con el tratamiento adecuado según las características especiales de cada caso. Este criterio, en mi opinión, incluso se relaciona con parámetros de proporcionalidad y rehabilitación apoyados en la concientización del agresor por el mal causado a la víctima.

Una de las principales características de la justicia restaurativa es la intervención de la víctima en el proceso de medicación toda vez que se le escucha y entiende. Una vez que se conoce lo que la víctima tiene interiorizado (sentimientos, recuerdos, tensiones, etc.) le transmite esto al agresor, así él se entera de algo que tal vez nunca supo - y que tampoco lo iba a saber - si no se lleva a cabo el proceso restaurativo y en su lugar, simplemente se aplicaba el castigo. En tal sentido, absurdo sería, continuar aplicando la retribución a sabiendas de su resultado perjudicial, por lo tanto es lógico que se concedan nuevas oportunidades a ideas innovadoras y diferentes a las fracasadas toda vez que no se pueden conseguir resultados distintos si se sigue aplicando la misma fórmula.

En ocasiones, al hablar de la mediación ciertos autores relacionan esta con la privatización de la justicia, lo cual sin duda es errado. Lo que sí es verdad, es que en los casos de violencia de género lo que ha sucedido en los últimos años es una suerte de extrema estatización de la justicia. En consecuencia de ello la Fiscalía se

Vid. Oubiña Barbolla, S.: “La dista..., op., cit., pp. 190-193. 
apodera del criterio de la víctima bajo el pretexto de que esta no es capaz de salir del círculo maltratador, creando así aún más tensión en la maltratada e incluso, en ocasiones, obligándole a esta a rendir testimonio en contra de su voluntad ${ }^{33}$.

Si bien es cierto, la violencia machista es inaceptable y deberá ser sancionada, sin embargo no por ello podemos cosificar a la víctima aumentando aún más la victimización, obligándola a presentarse al procedimiento y continuar con la acusación. Al parecer el Estado cumple aquí una suerte de defensa divina de la víctima, lo cual en la práctica no se constata, de ahí que en el ejercicio diario lo que se observa en lugar de una defensa de la víctima es una

33 He tenido la suerte - o desgracia - de conocer el criterio de una fiscal (de la cual prefiero reservar su nombre) que me impartió una clase sobre violencia de género y su tratamiento judicial. Ella, efectivamente defiende la prohibición de la mediación en supuestos de violencia de género.

En especial me llamó la atención cuando dijo que muchas veces las víctimas denunciaban a sus agresores el momento de ser maltratadas, sin embargo en lo posterior (etapa de juicio) se negaban a dar su testimonio. La fiscal lo que proponía como solución en estos supuestos era obligar a la víctima a presentarse en el juicio para que de su testimonio y si ella, en su testimonio, no decía "la verdad", su declaración se debía confrontar con lo que reza la denuncia presentada anteriormente por ella. Dentro de esa misma línea llegó a plantear una necesaria modificación de la ley que permita fungir a la denuncia presentada por la víctima como su testimonio en el juicio. Ella justificaba lo anterior debido que, a su criterio, la víctima carecía de voluntad propia al momento del juicio toda vez que ya había transcurrido mucho tiempo desde las agresiones y pretendía regresar al círculo maltratador del cual la Fiscalía la debía salvar. Como se podrá constatar, esta idea inclusive destruye principios procesales básicos como es la contradicción, oralidad o inmediación verificándose incluso, en casos extremos, el arrebatamiento de la voluntad de la víctima y el consiguiente apoderamiento extremo del litigio por parte del Estado que actúa "a favor" de la víctima pero irónicamente en contra de su voluntad. 
persecución al maltratador olvidándose, evidentemente, de las necesidades que emergen de la mujer maltratada y doblemente maltratada por el mismo sistema de justicia.

Hay que recordar al lector que la mediación penal no supone impunidad, en tal sentido se entenderá que si bien por una parte el proceso restaurativo se muestra a favor de la recuperación de la víctima, este tampoco se olvida del cumplimiento de la ley, por tanto, el maltratador siempre tendrá consecuencias por sus actos.

En el entorno de nuestra cultura jurídica es común que se descontextualice a la mediación penal como herramienta restaurativa. En efecto, cuando se habla se mediación penal por muchas ocasiones se ve aquella vía como la forma más fácil de evitar el cumplimiento de una pena y aquello no constituye más que una tergiversación de este recurso.

Las concepciones primitivas respecto a esta herramienta se dividen, a mi criterio, básicamente en dos: La primera, comúnmente pensada por el procesado, quien cree que al llegar a un acuerdo restaurativo evita completamente cualquier tipo de sanción o consecuencia del delito entregando cierta cantidad de dinero a la víctima. La segunda, preconcebida por la víctima, quien cree que solamente podrá recibir una compensación económica como reparación, lo cual muchas veces crea en ella la sensación de impunidad.

Aquellas incorrectas concepciones de lo que constituye la mediación penal obedecen a ciertos factores relacionados con la falta de preparación de los servidores judiciales y abogados que prestan sus servicios a la comunidad. En tal sentido no se 
podrá imputar el desconocimiento de este tema a los usuarios del sistema de justicia toda vez que estos constituyen meros receptores de lo que la administración de justicia o sus abogados les informan sobre los actuales procedimientos judiciales. En todo caso lo que se debería buscar por parte del Estado, la administración de justicia, los abogados e incluso estudiantes de derecho es reafirmar e impulsar la mediación penal como herramienta restaurativa eficiente y transparente.

Para contrarrestar las erradas preconcepciones que se han venido constatando respecto a la mediación penal, es necesario resaltar ciertas características que reafirma su utilidad en casos de violencia de género:

1. Con relación a la víctima: El fin último de la mediación penal constituye la reparación de esta. A través de la mediación la víctima podrá participar activamente en la resolución del conflicto, de tal manera que ella, con ayuda del mediador, dará a conocer lo que tiene interiorizado sobre el problema. Con este ejercicio la víctima puede exponer su punto de vista con relación al origen del inconveniente siendo ello, algo que sin duda, ayuda a su recuperación. Cuestión que evidentemente no se cumple en un procedimiento contencioso toda vez que el procesado con la sentencia condenatoria no puede ser obligado a escuchar lo que la víctima ha querido decir sobre las causas del conflicto y sus consecuencias.

2. Respecto a la reparación realizada por parte del ofensor, esta no deberá ser, en ningún caso, entendida como mera o exclusivamente económica.La reparación 
económica suele aplicarse, sin embargo, a más de ello existen un sin número de formas con las cuales el ofensor puede reparar el daño causado a la víctima, lo cual dependerá de las condiciones de la mediación e incluso del criterio de la misma maltratada. En tal sentido, no es extraño que en un proceso de mediación se acuerden ciertas actividades extrañas a fines económicos que deberán ser realizadas por parte del ofensor en pro de la recuperación de la víctima.

3. Con relación al ofensor: Con el proceso contencioso tradicional lo que se obtiene para el ofensor son penas puras y duras. Así, el maltratador cumple el castigo sin tener la posibilidad de razonar su mala conducta en conjunto con la víctima lo cual no permite que el delincuente comprenda claramente las consecuencias generadas en la maltratada. Además de ello, con el sistema contencioso es imposible que el ofensor conozca los sentimientos causados en la víctima, lo que ella piensa sobre él, los miedos que recorren su cuerpo y en general la tragedia que supone una relación maltratadora.

Por otra parte, el ofensor luego de todo el proceso de mediación podrá, en ciertos casos -que dependerán de cada legislación-, beneficiarse de la mediación para conseguir penas alternativas o beneficios penitenciarios, los cuales evidentemente no se podrán confundir con la impunidad toda vez que existe una consecuencia jurídica del delito que por una parte sanciona, pero en definitiva, resocializa observando hacia al futuro. 
4. Con relación a la justicia: Mediante la aplicación de este procedimiento restaurativo se tiende a una respuesta penal educativa y centrada en la prevención del delito, buscando la responsabilización y concientización de los maltratadores y la respectiva reparación a la víctima.

Por lo motivos antes expuestos, a mi criterio, la mediación penal en asuntos de violencia de género podría ser aplicada con excelentes resultados, sin embargo, lo que si se tiene que advertir es la selección de casos. Como se dijo anteriormente, lo que se busca con la mediación penal y los procesos restaurativos es beneficiar a la víctima, por ello, no se podrá llevar a cabo la mediación penal en relaciones crónicas con antecedentes irreparables toda vez que aquello sería contrario al fin mismo de la mediación en un plano restaurativo. El maltrato inicial, las agresiones leves y eventuales, entre otros, son las situaciones en las cuales se debe intervenir desde esta vía, buscando así una rehabilitación de las partes, consiguiéndose incluso, la rehabilitación de la relación que paradójicamente es contraria a lo que busca el paradigma legal actual ${ }^{34}$.

\section{¿LA JUSTICIA RESTAURATIVA HA TENIDO ÉXITO?}

La justicia restaurativa desde su implantación ha tendido a arrojar mejores resultados que la justicia retributiva. Los porcentajes de satisfacción por parte de las víctimas se encuentra entre el 90 y 80 por ciento, mientras que la satisfacción de los ofensores oscilan

34 Sobre este tema véase EsQUINAS VALVERDE, P: Mediación entre víctima y agresor en la violencia de género, Tirant Monografías, Valencia, 2008, pp. 122-133. 
entre el 70 al 90 por ciento ${ }^{35}$. Estas cifras de satisfacción, sin duda son mayores a las obtenidas por la justicia tradicional, sin embargo hay que recordar, como lo hemos dicho anteriormente, la justicia contenciosa solamente tiene dos respuestas al usuario: ganar o perder mientras que la justicia restaurativa se basa en la voluntariedad de las partes para llegar a acuerdos, por lo tanto, es lógico que este sistema, incluso por su carácter de voluntario, tenga mayor porcentaje de satisfacción, sin embargo, todos los indicadores de complacencia, sobrepasan, por mucho, las cifras obtenidas por la justicia contenciosa.

En el sentido anterior, es importante revisar como referencia los resultados ya obtenidos en países como Nueva Zelanda y Australia, donde se han implantado procesos restaurativos en supuestos de violencia de género, obteniéndose de ello consecuencias positivas. Uno de los mecanismos más aplicados para casos de violencia de género con relaciones de poder y desigualdad entre las partes, es la mediación indirecta o shuttle mediation aplicada dentro de la mediación víctima - ofensor ${ }^{36}$. Una de las principales características de la mediación víctima - ofensor es la vista cara a cara entre víctima y agresor, sin embargo en los casos en los que existe una desigualdad de poder entre las partes, con el fin de que aquello no lesione las voluntades, se apuesta por la mediación indirecta o la presencia de una tercera persona que apoya a la víctima.

35 Datos tomados de países anglosajones, extraído de TAMARIT SUMALLA, J.: "La just..., op., cit., p. 30. Que a su vez cita como fuente a Umbreit, Vos y Coates.: "The impact of restorative justice confering: a multi-national perspective", British Journal of Community Justice, v. 1,2002 , pp. 22 ss.

Villacampa Estiarte, C.: “La just..., op., cit., p. 112. 
Igualmente, para mitigar el predominio de poder del maltratador frente a la víctima, ha surgido una corriente que apoya lo que se conoce como la mediación online ${ }^{37}$ que evidentemente genera mayor seguridad a la víctima al momento de confrontar al agresor e intentar un proceso restaurativo.

\section{CONCLUSIÓN}

En manos del Estado y más concretamente del Poder Legislativo se encuentra la potestad de dar el tratamiento penal correcto a la violencia de género. Tradicionalmente ha existido una sola vía, la punitiva, sin embargo aquello en la actualidad ha cambiado y se han presentado distintas formas de solventar estos conflictos. En tal sentido es necesario nuevamente citar a ZAFFARONI que explica con elocuencia lo siguiente:

Imaginemos que un niño rompe a patadas un vidrio en la escuela. La dirección puede llamar al padre del pequeño energúmeno para que pague el vidrio, puede enviarlo al psicopedagogo para ver qué le pasa al chico, también puede sentarse a conversar con el pibe para averiguar si algo le hace mal y lo irrita. Son tres formas de modelos no punitivos: reparador, terapéutico y conciliatorio. Pueden aplicarse los tres modelos porque no se excluyen. En cambio, si el director decide que la rotura del vidrio afecta a su autoridad y aplica el modelo punitivo expulsando al niño, ninguno

37 Sobre este tema véase CARRETERO, E.: "Mediación online: una posible vía para introducir la justicia restaurativa en los asuntos de violencia de género" Sobre la mediación penal (posibilidades y limites e un entorno de reforma de Proceso Penal Español), Aranzadi, Pamplona, 2012, pp. 211-241. 
de los otros puede aplicarse. Es claro que el director, al expulsar al niño, refuerza su autoridad vertical sobre la comunidad escolar. Es decir, que el modelo punitivo no es un modelo de solución de conflictos, sino de decisión vertical de poder..$^{38}$

Por lo tanto, se deberá decidir si lo que se busca por parte del Estado es la reafirmación de la verticalización del poder o en su defecto, y para beneficio de la sociedad, una solución real y efectiva del problema.

En suma, lo que se pretende con el presente trabajo es visibilizar los prejuicios del sistema actual con relación a la prohibición de la mediación penal en supuesto de violencia de género, dando ciertos fundamentos que a mi criterio, son necesarios resaltar para justificar la implementación de procedimientos restaurativos en respuesta a la violencia machista. Como se ha constatado a lo largo del presente aporte, existen un sin número de argumentos que apoyan la implementación de la mediación penal en asuntos de violencia de género, ahora queda, a criterio del legislador, tomar cartas en el asunto, o esperar cambios sin que nada cambie.

ZAFFARONI, E.: La cuestión..., op., cit., p. 25. 


\section{BIBLIOGRAFÍA}

BECCARIA, C.: Tratado de los delitos y las penas, Universidad Carlos III de Madrid, Madrid, 2015.

BECK, U.: La sociedad de riesgo. Hacia una nueva modernidad, Paidós, Barcelona, 1998.

CANO Soler, M.A.: La mediación penal, Aranzadi, Pamplona, 2015.

CARRETERO Morales, E.: "Mediación online: una posible vía para introducir la justicia restaurativa en los asuntos de violencia de género" Sobre la mediación penal (posibilidades y limites e un entorno de reforma de Proceso Penal Español) (Dir. Pedro M. Garciandía González y Helena Sotelo), Aranzadi, Pamplona, 2012, pp. 211-241.

DÍAZ Madrigal,I.N.: La mediación en el sistema de justicia penal: justicia restaurativa en México y España, Universidad Nacional Autónoma de México, México DF, 2013.

ESQUINAS Valverde, P: Mediación entre víctima y agresor en la violencia de género, Tirant Monografías,Valencia, 2008.

MERA González-Ballesteros, A.: "Justicia restaurativa y proceso penal garantías procesales: límites y posibilidades", Revista Ius et Praxis, No 2, 2015, pp. 165-195 
NIEVES Loja, G.: "El carácter reconstructivo de la justiciaindígena, Chimborazo, Ecuador: perspectiva ética.", Aufklärung: revista de filosofía, V2.N2, 2015, pp. 79-102.

OUBIÑA Barbolla, S.: "La distancia que les separa, la distancia que nos separa: mediación en casos de violencia doméstica en España y en otros sistemas." Sobre la Mediación Penal (posibilidades y limites en un entorno de reforma del Proceso Penal Español) (Dir. Pedro M. Garciandía González y Helena Soleto), Aranzadi, Pamplona, 2012, pp. 179-204.

PERUlero García,D: "Hacia un modelo de justicia restaurativa: la mediación penal.”,Sobre laMediación Penal (posibilidades $y$ limites en un entorno de reforma del Proceso Penal Español) (Dir. Pedro M. Garciandía González y Helena Soleto), Aranzadi, Pamplona, 2012, pp. 69-89.

SILVA Sánchez, J.M.: La expansión del derecho penal aspectos de la política criminal en las sociedades postindustriales, Civitas, Madrid, 2001.

TAMARIT Sumalla, J.: "La justicia restaurativa: concepto, principios, investigación y marco teórico", La justicia restaurativa: desarrollo y aplicaciones (coord. Josep Tamarit Sumalla), Comares, Granada, 2012, pp. 3-60.

VILlACAMPA Estiarte, C.: "La justicia restaurativa en los supuestos de violencia doméstica (y de género)", La justicia restaurativa: desarrollo yaplicaciones (coord. Josep Tamarit Sumalla), Comares, Granada, 2012, pp. 89-130. 
Carlos Serrano Lucero

Justicia RESTAURATIVA

ZAFFARONI, E.: Estructura básica del derecho penal, Ediar, Buenos Aires, 2011.

. La cuestión criminal, Ibáñez, Bogotá, 2013. 